\title{
Cronograma de amostragem de alface cultivada em hidroponia para ajuste de curvas de crescimento vegetativo
}

\author{
Sidinei José Lopes( ${ }^{(1)}$, Paula Machado dos Santos(1), Lindolfo Storck ${ }^{(1)}$, Carine Cocco(1), Henrique Perin Damo(1) \\ e Luís Fernando Dias Martini(1)
}

\begin{abstract}
(1) Universidade Federal de Santa Maria, Centro de Ciências Rurais, Dep. de Fitotecnia, Av. Roraima, s/no, Bairro Camobi, CEP $97105-900$ Santa Maria, RS. E-mail: sjlopes@pop.com.br, paulagron@hotmail.com, lindolfo@smail.ufsm.br, carinecocco@yahoo.com.br, hpdamo@bol.com.br, martini@hotmail.com
\end{abstract}

\begin{abstract}
Resumo - O objetivo deste trabalho foi determinar o cronograma de amostragem de plantas de alface hidropônica, para ajuste de curvas de crescimento durante o período vegetativo. Foram realizados dois cultivos de alface, variedade Regina, de 8/9/2004 a 19/11/2004 (primavera/verão) e 22/2/2005 a 24/5/2005 (verão/outono), em estufas de plástico do Dep. de Fitotecnia, da UFSM, Santa Maria, RS. A partir do ajuste do modelo co-seno com amostragem diária, registrada como padrão, diferentes intervalos entre as amostragens foram simulados para o ajuste do mesmo modelo. A fim de se encontrar o intervalo adequado, foi comparada a variância de falta de ajuste do modelo de amostragem diária com as variâncias de falta de ajuste dos modelos com diferentes intervalos de amostragens pelo teste F. Os cronogramas de amostragens para ajuste de curvas de crescimento de plantas de alface sob hidroponia, para experimentos de primavera/verão e verão/outono, possuem intervalos iguais a dois dias, para fitomassa seca total da planta e da folha; intervalos de quatro dias, para fitomassa de raiz; e, diariamente, para área foliar.
\end{abstract}

Termos para indexação: Lactuca sativa, variância, fitomassa, área foliar.

\section{Sampling chronology of hydroponics lettuce plants for adjusting vegetative growth curves}

\begin{abstract}
The objective of this work was to determinate a sampling chronology to adjust lettuce hidroponic growth curves during its vegetative development. The variety Regina was grown from September 8, 2004 until November 19, 2004 (spring/summer) and February 22, 2005 until May 24, 2005 (summer/fall). Plants were placed inside a plastic covered greenhouse in Santa Maria, RS, Brazil. Based on the adjusted cosine model, daily samples were taken as standard and different sampling intervals were simulated in order to better adjust the same model. To estimate de adequate sampling interval a comparison was conducted between the variance of lack of adjustment of the daily sampling with the variance of lack of adjustment of different samplings intervals using an F test. Sampling chronograms for adjusting crop growth curves of hydroponics lettuce plants for both spring/ summer and summer/fall seasons present a time interval of two days for total plant or leaf dry weight and four days intervals for root dry weight or leaf area.
\end{abstract}

Index terms: Lactuca sativa, variance, phytomass, leaf area.

\section{Introdução}

$\mathrm{O}$ crescimento vegetativo que finda com o início do pendão floral é uma das fases mais importantes na produção da alface (Lactuca sativa L.). Durante a fase vegetativa, a maior parte dos fotoassimilados é direcionada à área foliar. Esse aumento de área foliar é acompanhado pelo aumento proporcional na interceptação de energia, já que as plantas vizinhas são pequenas e o sombreamento mútuo quase não existe. A fitomassa das plantas individuais aumenta, diariamente, numa proporção constante, conduzindo a um crescimento exponencial. Após a cultura fechar a superfície, em uma segunda fase, mais folhas crescem sem conduzir a mais interceptação de luz. Nessa segunda fase, a maior parte do total de fitomassa seca é formada (Van Keulen \& Wolf, 1986).

A tendência da agricultura moderna é desenvolver modelos para simulação de crescimento, com objetivo de detectar os fatores que possam limitar o crescimento, influindo no potencial produtivo das espécies (Lopes et al., 2004). O ajuste nas curvas de crescimento permite prever a época de colheita e decidir o momento mais apropriado para a coleta de 
amostras de plantas. Na utilização dos modelos matemáticos de crescimento e desenvolvimento de plantas, é necessário determinar suas constantes empíricas por meio da avaliação de fitomassa em períodos regulares, isto é, uma determinada cronologia ou frequiência de amostragem.

Quanto ao ajuste de curvas de crescimento sob ambientes controlados, a frequiência da realização de coletas de amostras exigidas, restringe, muitas vezes, o número de efeitos de tratamentos a serem estudados, pois a área experimental é restrita. Normalmente são realizadas coletas semanais para o estudo do crescimento da cultura de alface, porém, com a primeira coleta em diferentes números de dias após o transplante.

Nos experimentos com a cultura de alface, a fim de modelar o crescimento e o desenvolvimento de plantas, as amostragens variam de coletas a cada cinco dias, até coletas semanais (Segovia et al., 1997; Andriolo et al., 2003; Radin et al., 2004), ou seja, não ultrapassam dez dias de amostragens durante o ciclo vegetativo da cultura. Com isso, é importante determinar o cronograma de coleta das amostras de plantas a fim de ajustar as curvas de crescimento, buscando reduzir o efeito destrutivo das amostragens, sem comprometer a precisão dos modelos, e evitar o desperdício de tempo, material e recursos financeiros.

O objetivo deste trabalho foi determinar o cronograma de amostragem de plantas de alface hidropônica, para ajuste de curvas de crescimento durante o período vegetativo.

\section{Material e Métodos}

Foram conduzidos dois experimentos, um na primavera/verão, de 8/9/2004 a 19/11/2004, e outro no verão/outono, de 22/2/2005 a 24/5/2005, em estufa de plástico do Dep. de Fitotecnia da Universidade Federal

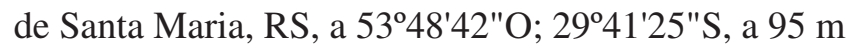
de altitude.

Os experimentos foram conduzidos com a técnica de fluxo laminar (NFT), de cultivo em hidroponia, em bancadas de perfis hidropônicos médios de $6 \mathrm{~m}$ de comprimento (Hidrogood), sob estufa de plástico de 10x25 m, com piso de concreto, coberta com policloreto de vinil plastificado e com espessura de $0,2 \mathrm{~mm}$, aditivado contra raios ultravioletas. A solução nutritiva utilizada foi a proposta por Castellane \& Araújo (1995).
A variedade de alface cultivada foi a Regina do tipo lisa, indicada para plantio durante todo o ano.

As mudas foram produzidas em espuma fenólica e transplantadas para as bancadas de perfis hidropônicos, quando apresentavam duas folhas verdadeiras (não cotiledonares). O espaçamento entre plantas foi de $0,25 \times 0,25 \mathrm{~m}$, com 450 plantas úteis. Iniciou-se a contagem do número de dias após o transplante (DAT) até completar 45 dias e 70 dias das estações de primavera/verão e verão/outono, respectivamente, quando se verificou visualmente o início de estiolamento das plantas, ou seja, o início do período reprodutivo. Diariamente, às $8 \mathrm{~h}$ da manhã, foram retiradas aleatoriamente três plantas para avaliação. Foi utilizada bordadura mínima de uma planta em todos os lados de cada planta retirada. As características avaliadas em cada planta foram a fitomassa seca da raiz, do talo e das folhas (verdes e senescentes) e a área foliar estimada pelo método de discos foliares, em que foram extraídos discos de todas as folhas da planta com auxílio de um vazador de 0,018 m de diâmetro, até um limite máximo de 50 discos por planta.

A temperatura máxima e mínima do ar de cada dia foi verificada no interior da estufa, às $18 \mathrm{~h}$, em um termômetro de máxima e mínima, localizado à altura de $1,50 \mathrm{~m}$, a fim de estimar a variável independente graus-dia (GD).

O valor relativo acumulado da variável GD, para o i-ésimo dia, foi estimado por:

$$
\begin{aligned}
& \operatorname{GDr}_{\mathrm{i}}=\sum_{\mathrm{j}=1}^{\mathrm{ni}}\left(\overline{\mathrm{T}}_{\mathrm{j}}-\mathrm{T}_{\mathrm{B}}\right) / \mathrm{GD}_{\mathrm{pmf}}, \text { para } \mathrm{TB} \leq \overline{\mathrm{T}} \mathrm{j}, \\
& \overline{\mathrm{T}}_{\mathrm{j}}=\frac{\operatorname{Tmáx}_{\mathrm{j}}+\operatorname{Tmín}_{\mathrm{j}}}{2}
\end{aligned}
$$

sendo $\mathrm{T}_{\mathrm{j}}$, a temperatura média diária do ar $\left({ }^{\circ} \mathrm{C}\right)$ do dia j; Tmáx ${ }_{\mathrm{j}}$ e Tmín ${ }_{\mathrm{j}}$, as temperaturas $\left({ }^{\circ} \mathrm{C}\right)$ máxima e mínima do ar; $G_{\mathrm{pmf}}$ é o GD acumulado correspondente ao ponto de maturidade fisiológica ou o $\mathrm{GDr}_{\mathrm{i}}$ do $45^{\circ} \mathrm{C}$ (primavera/verão) e $70^{\circ} \mathrm{C}$ (verão/ outono) DAT; e $\mathrm{T}_{\mathrm{B}}$, a temperatura basal da cultura de alface $\left(10^{\circ} \mathrm{C}\right.$, Brunini et al., 1976).

Quanto à fitomassa seca total $(\mathrm{FST}=$ raiz + talo + folhas), de folhas (FSF) e de raízes (FSR) e área foliar (AF), pressupôs-se que seu valor máximo foi alcançado no ponto de maturidade fisiológica, quando taxa de acúmulo é nula, ocorrido geralmente próximo do desenvolvimento relativo $\left(\mathrm{GDr}_{\mathrm{i}}\right)$ equivalente a 1 . Para cada uma das quatro características, variáveis 
dependentes, foram calculadas as quantidades das variáveis acumuladas no i-ésimo dia e dividido pelo respectivo valor máximo (Lopes et al., 2004), obtendose os valores relativos.

Posteriormente, para cada uma das quatro variáveis dependentes, foi ajustado o modelo co-seno (Dourado Neto et al., 1998), com a introdução das constantes $\alpha, \beta$ e $\delta$, consideradas como fator de forma da curva de crescimento, obtidas empiricamente, segundo critérios de ajuste:

$\hat{\mathrm{Yr}}_{\mathrm{i}}=\frac{\cos ^{\alpha}\left\{\frac{\pi}{2}\left(1-\mathrm{GDr}_{\mathrm{i}}\right)^{\beta}\right\}}{\delta},(\alpha, \beta, \delta \in \mathfrak{R})$

$\mathrm{Na}$ estimação das constantes deste modelo, foi usado o programa Table Curve 2D v.2.03 (Jandel Scientific), que usa o procedimento iterativo para mínimos quadrados não-lineares de LevembergMarquardt (Lopes et al., 2004). Além das estimativas das constantes, foram obtidos, para cada modelo, os graus de liberdade (GL) e o quadrado médio do erro ou variância da falta de ajuste (QME).

Neste trabalho, definiu-se o cronograma de amostragem como sendo o número de dias de intervalo entre duas amostragens consecutivas. Assim, um maior intervalo entre amostragens equivale a menor número de amostragens durante o ciclo vegetativo da planta.

Os modelos ajustados, usando dados dos 45 e 70 dias das estações de primavera/verão e verão/ outono, respectivamente, foram considerados como padrão para a comparação com os outros modelos. Outros modelos foram ajustados usando diferentes número de dias de intervalos $(\mathrm{k})$ entre duas coletas sucessivas de plantas. Simularam-se intervalos de dois a dez dias entre uma coleta de dados e outra, a partir do primeiro DAT.

Foi encontrado o maior valor de $\mathrm{k}$ (número de dias de intervalo entre uma coleta e outra) tal que a falta de ajuste de modelo (QMEk) com intervalo de $\mathrm{k}$ dias, em que o QMEk não diferisse da falta de ajuste do modelo-padrão (QME). O teste usado foi o da razão das estimativas de máxima verossimilhança da variância residual, ou seja, os quadrados médios do erro da análise de regressão não-linear com os respectivos graus de liberdade (Ratkowsky, 1983), a $5 \%$ de probabilidade. Foi considerado como cronograma adequado de amostragem o caso de maior número de dias de intervalo que não diferisse da amostragem diária (modelo-padrão).
O início da contagem de DAT, para fins do ajuste do modelo de crescimento, é um tanto subjetivo e, com a finalidade de melhorar a confiabilidade da decisão, foram consideradas sete possibilidades de início da contagem para encontrar o valor de k. Assim, para cada época e característica, as coletas foram iniciadas a partir do primeiro, do segundo, do terceiro, do quarto, do quinto, do sexto e do sétimo DAT. Para cada possibilidade, foi encontrado o valor de $\mathrm{k}$ (intervalo adequado).

Adotou-se, como critério de escolha do intervalo adequado de amostragem, o valor modal entre as sete possibilidades de início. Quando a moda não estava presente, optou-se pelo menor valor de $\mathrm{k}$ entre as sete possibilidades.

\section{Resultados e Discussão}

Observaram-se durante os experimentos, temperaturas mínimas e máximas do ar acima da faixa de temperatura do ar ideal para o pleno crescimento e desenvolvimento da planta, de 4,4 a $21,1^{\circ} \mathrm{C}$ (Silva et al., 1999; Mattos et al., 2001), acelerando o ciclo e antecipando o momento de colheita. As médias das temperaturas máxima, mínima e média do ar foram, respectivamente, 28,12 e $20^{\circ} \mathrm{C}$, durante o experimento de primavera/verão; no experimento de verão/outono, foram 31,21 e $26^{\circ} \mathrm{C}$, respectivamente. A partir de 40 dias, aproximadamente, após o transplante, o talo passa a receber uma parcela importante da fitomassa total da planta em detrimento das folhas (Segovia et al., 1997). Brunini et al. (1976) comentam que temperaturas altas são responsáveis pela emissão do talo.

Os modelos de crescimento da fitomassa seca relativa total (Figura $1 \mathrm{~A}$ ) da folha (Figura $1 \mathrm{C}$ ), da raiz (Figura $2 \mathrm{~A}$ ) e da área foliar (Figura $2 \mathrm{C}$ ), no cultivo hidropônico da alface, pela coleta diária das plantas, no cultivo de primavera/verão, mostram boa qualidade de ajuste do modelo co-seno, usando as constantes $\alpha, \beta$ e $\delta$, pois o coeficiente de determinação $\mathrm{R}^{2}$ é alto, e é importante para validar o uso do modelo na construção de curvas de crescimento para o cultivo de alface hidropônica. No cultivo de verão/outono (Figuras 3 e 4), a situação da qualidade do ajuste se repete. A qualidade dos ajustes dos mesmos modelos, nos casos em que a freqüência de amostragem é menor (menor número de dados) a qualidade do ajuste também é boa, no ciclo primavera/verão (Figuras 1 B e 2 D) e no ciclo de verão/outono (Figuras 3 B e 4 D). Para fins de 
comparação, mantêm-se os pontos correspondentes ao desenvolvimento relativo $\left(\mathrm{Dr}_{\mathrm{i}}\right)$ da amostragem diária.

O cronograma de amostragem ou intervalo adequado de amostragem de plantas de alface, para estimar as curvas de crescimento, é apresentado nas Figuras 1, 2, 3 e 4. Assim, deve-se amostrar a cada dois (FST e FSF), quatro (FSR) e um (AF) dia na época da primavera e a cada dois (FST), três (FSF), quatro (FSR) e um (AF) dia na época do outono. Com esses intervalos de dias entre as amostragens (k), a variância de falta de ajuste do modelo co-seno com três constantes não difere da variância da falta de ajuste do mesmo modelo na amostragem diária. Além disso, o coeficiente de determinação (quadrado do coeficiente de correlação linear) entre os valores estimados pelos modelos, ao usar amostragem diária, e os valores estimados pelos mesmos modelos, ao usar intervalos de $\mathrm{k}$ dias entre as amostragens, variaram entre $94 \mathrm{e}$ $99 \%$. Desta forma, na amostragem a cada $\mathrm{k}$ dias, as estimativas das constantes do modelo co-seno não são influenciadas pela amostragem com intervalos maiores do que a diária. Uma correlação alta, no caso deste trabalho, mostra eficiência do modelo ajustado, usando amostragem com intervalos maiores do que a de um dia, e também possibilita a economia de trabalho e de material experimental.

Existem casos em que o valor do $\mathrm{R}^{2}$ do modelo com amostragem diária é menor que o modelo com $\mathrm{k}$ dias de intervalo de amostragem, caracterizando
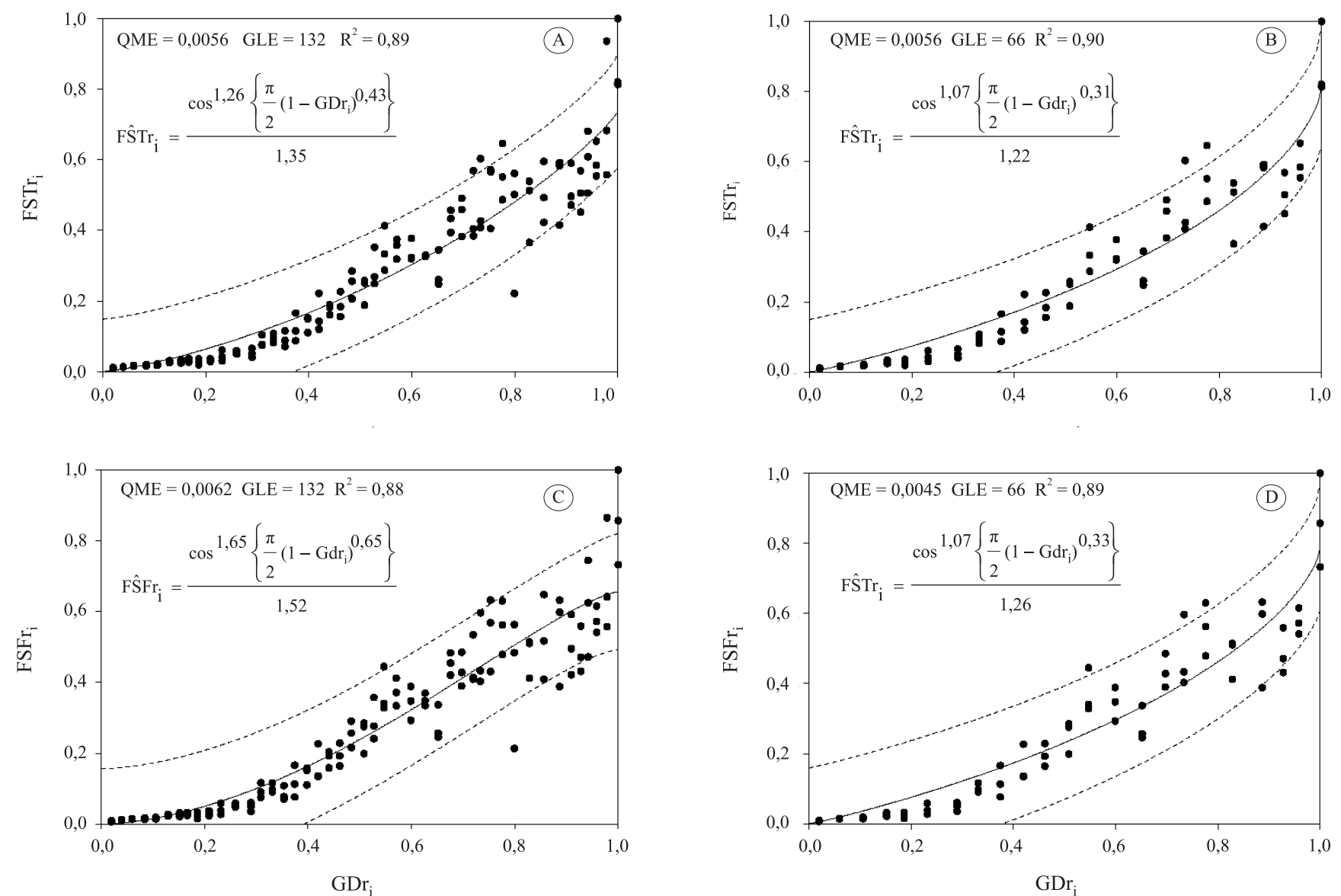

Figura 1. Faixa de $95 \%$ de confiança do modelo do co-seno estimando a fitomassa seca relativa total (FST) da planta de alface hidropônica pelas coletas de amostras diárias (A) e com intervalos de dois dias (B); e estimando a fitomassa seca relativa de folha (FSF) pelas coletas de amostras diárias (C) e com intervalos de dois dias (D) no experimento de primavera de acordo com o desenvolvimento relativo em graus-dias acumulados $\left(\mathrm{GDr}_{\mathrm{i}}\right)$, e seus respectivos quadrados médios do erro (QME), graus de liberdade do erro (GLE) e coeficiente de determinação do modelo $\left(\mathrm{R}^{2}\right)$. 

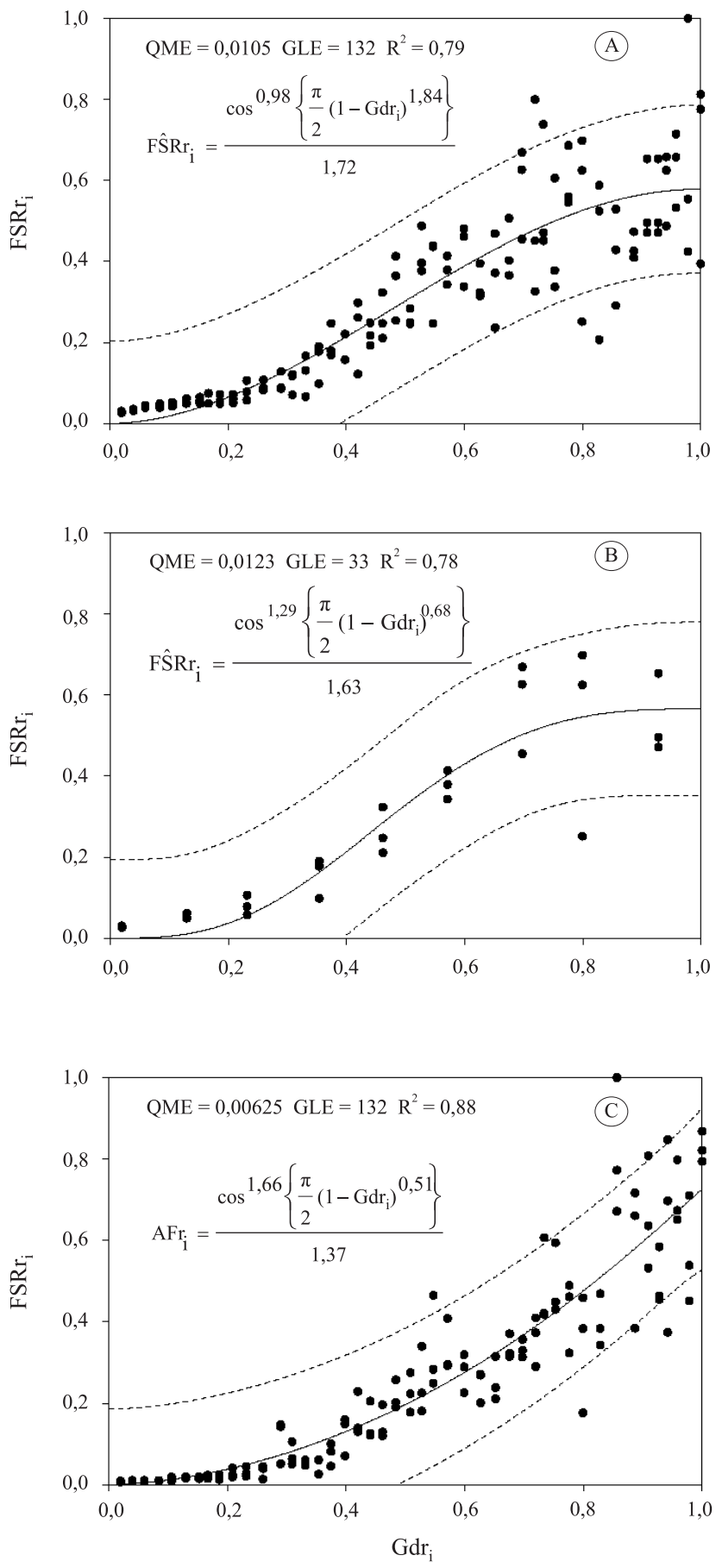

Figura 2. Faixa de $95 \%$ de confiança do modelo do co-seno estimando a fitomassa seca relativa de raiz (FSR), na cultura de alface hidropônica pelas coletas de amostras diárias (A) e com intervalos de quatro dias (B); e estimando a área foliar relativa (AF) pelas coletas de amostras diárias (C) no experimento de primavera, de acordo com o desenvolvimento relativo em graus-dias acumulados $\left(\mathrm{GDr}_{\mathrm{i}}\right)$, e seus respectivos quadrados médios do erro (QME), graus de liberdade do erro (GLE) e coeficiente de determinação do modelo $\left(\mathrm{R}^{2}\right)$. intervalos maiores entre coletas de amostras como modelos de maior precisão. Porém, considerando que a amostragem diária explica realmente o crescimento das plantas, qualquer amostragem que não seja diária pode, aleatoriamente, obter melhor ajuste ao modelo, porém não explica a verdadeira variabilidade do crescimento.

Esses resultados são importantes para planejar adequadamente a quantidade de material experimental e os recursos humanos necessários. Demonstrou-se, assim, que o intervalo de amostragens adequado, verificado para alface hidropônica, necessita ser menor do que os utilizados em vários trabalhos científicos para análise quantitativa de crescimento de comunidades vegetais, que variam entre 5 e 14 dias (Pereira \& Machado, 1987; Lima, 1995).

A utilização de intervalos maiores entre as amostragens pode prejudicar a interpretação dos modelos, devido à falta de precisão do modelo e aos desvios da estimação das constantes, ocorrendo modificação no comportamento da curva de crescimento, induzindo ao planejamento de práticas de manejo fora da real necessidade, segundo o crescimento e o desenvolvimento da planta.

Existem diferenças de intervalos de amostragens para as diferentes características (fitomassa da folha, da raiz e do total e da área foliar) analisadas, e o intervalo de amostragem depende mais da característica do que da época de cultivo. Normalmente, é coletada como amostra a planta inteira, e com as medidas individuais de partes da planta obtém-se a fitomassa seca total. Considerando-se ainda que o intervalo de amostragem para fitomassa seca total é o que exige menor intervalo entre amostragens de plantas no ciclo, a cada dois dias, para o experimento de verão/ outono e primavera/verão, pode-se sugerir este cronograma de coletas de plantas para o ajuste utilizado em curvas de crescimento que utilizem fitomassa de planta.

Quanto à fitomassa seca relativa de raiz, o intervalo entre amostragens é maior, se comparado com o das demais características, possivelmente em virtude de a taxa de crescimento da raiz ser mais 
constante que a das demais partes da planta. Ao planejar estimar a fitomassa seca relativa total da planta de alface, no momento da coleta, pode ser realizada a partição das demais partes da planta, que também se pretende estimar. Aparentemente, partes da planta com crescimento menor apresentam necessidade de intervalos maiores para realização de suas coletas. Lopes et al. (2004) expõem a hipótese de que o cultivo hidropônico depende basicamente da radiação solar e da temperatura do ar e que, nestes casos, o cronograma de amostragem deve ser diferente, conforme a disponibilidade desses fatores, ou seja, são necessários intervalos menores entre amostragens à medida que se aumenta o sombreamento da cultura e, conseqüentemente, se altera o microclima dentro da comunidade vegetal. Essa hipótese pode também estar relacionada com o aumento da dispersão dos resultados de fitomassa da planta na curva de crescimento, à medida que esse microclima dentro da comunidade vegetal é alterado, e a alocação de fotoassimilados distribuise diferentemente na planta, aumentando a variância entre amostras realizadas no mesmo dia, à medida que o crescimento relativo da cultura aumenta. Assim, pode-se propor a execução de outros trabalhos com o objetivo de avaliar diferentes intervalos de amostragens em diferentes fases do ciclo da cultura de alface.
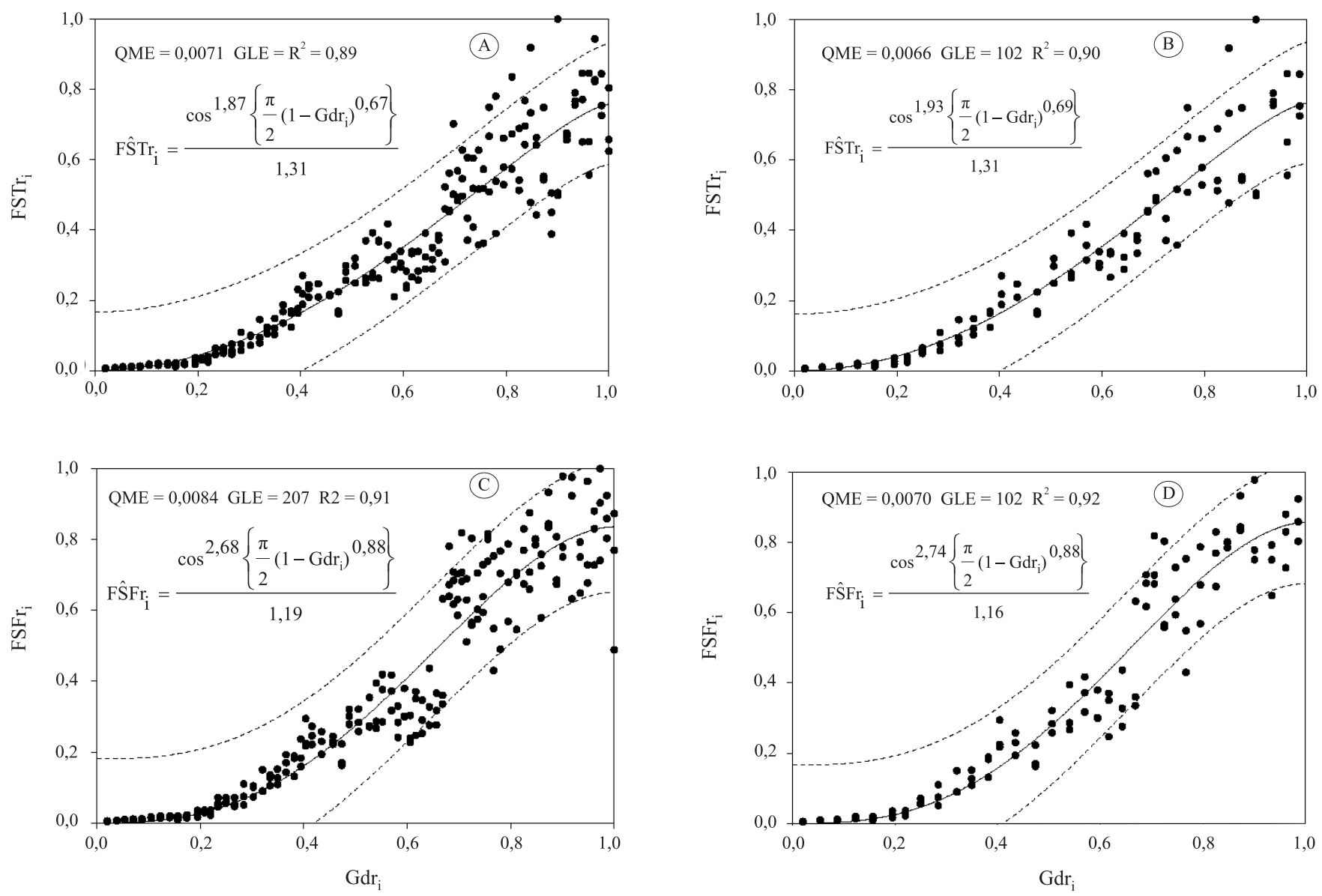

Figura 3. Faixa de $95 \%$ de confiança do modelo do co-seno estimando a fitomassa seca relativa total (FST) da planta de alface hidropônica pelas coletas de amostras diárias (A) e com intervalos de dois dias (B); e estimando a fitomassa seca relativa de folha (FSF) na cultura de alface pelas coletas de amostras diárias (C) e com intervalos de dois dias (D) no experimento de outono, de acordo com o desenvolvimento relativo em graus-dias acumulados $\left(\mathrm{GDr}_{\mathrm{i}}\right)$, e seus respectivos quadrados médios do erro (QME), graus de liberdade do erro (GLE) e coeficiente de determinação do modelo $\left(\mathrm{R}^{2}\right)$. 

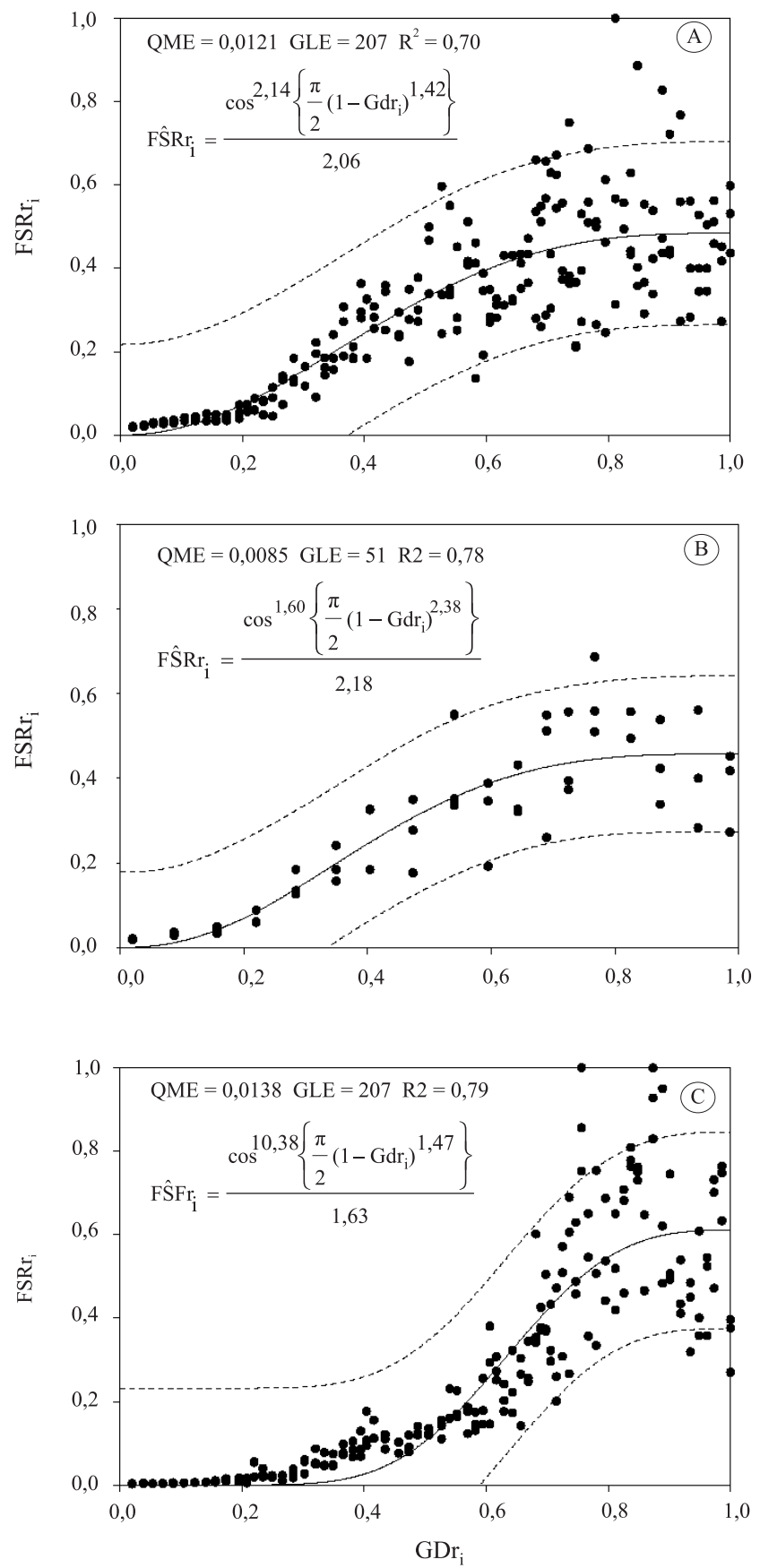

Figura 4. Faixa de $95 \%$ de confiança do modelo do co-seno estimando a fitomassa seca relativa de raiz (FSR) na cultura de alface hidropônica pelas coletas de amostras diárias (A) e com intervalos de quatro dias (B); e estimando a área foliar relativa (AF) na cultura de alface pelas coletas de amostras diárias (C), no experimento de outono de acordo com o desenvolvimento relativo em graus-dias acumulados $\left(\mathrm{GDr}_{\mathrm{i}}\right)$, e seus respectivos quadrados médios do erro (QME), graus de liberdade do erro (GLE) e coeficiente de determinação do modelo $\left(\mathrm{R}^{2}\right)$.

\section{Conclusões}

O cronograma de amostragem para o melhor ajuste de curvas de crescimento dos vários órgãos de plantas de alface sob hidroponia, em experimentos de primavera/verão e verão/ outono, deve ter intervalos de dois dias para fitomassa seca total da planta e de folha, intervalos de quatro dias para fitomassa seca de raiz e, diariamente, para a área foliar.

\section{Referências}

ANDRIOLO, J.L.; ESPINDOLA, M.C.G.; STEFANELLO, M.O. Crescimento e desenvolvimento de plantas de alface provenientes de mudas com diferentes idades fisiológicas. Ciência Rural, v.33, p.3540, 2003.

BRUNINI, O.; LISBÃO, R.S.; BERNARDINI, J.B.; FORNASIER, J.B.; PEDRO JÚNIOR, M.J. Temperatura-base para alface cultivar White Boston, em um sistema de unidades térmicas. Bragantia, v.35, p.213-219, 1976.

CASTEllane, P.D.; ARAÚJO, J.A.C. Cultivo sem solo: hidroponia. 4.ed. Jaboticabal: Funep, 1995. 43p.

DOURADO NETO, D.; TERUEL, D.A.; REICHARDT, K.; NIELSEN, D.R.; FRIZZONE, J.A.; BACCHI, O.O.S. Principles of crop modeling and simulation. I. Uses of mathematical models in agriculture science. Scientia Agricola, v.55, p.46-50, 1998.

LIMA, M.G. Calibração e validação do modelo Ceres-Maize em condições tropicais do Brasil. 1995. 119p. Tese (Doutorado) Universidade de São Paulo, Piracicaba.

LOPES, S.J.; DOURADO NETO, D.; MANFRON, P.A.; JASNIEWICZ, R. Models to estimate phytomass accumulation of hydroponic lettuce. Scientia Agricola, v.61, p.392-400, 2004.

MATTOS, K.M. da C. Efeito da temperatura do ar das canaletas e da estufa sobre o crescimento da alface (Lactuca sativa $\mathrm{L}$.) em sistema hidropônico em função do material de cobertura da bancada. 2000. 113p. Dissertação (Mestrado) - Universidade de São Paulo, Piracicaba.

PEREIRA, A.R.; MACHADO, E.C. Análise quantitativa do crescimento e desenvolvimento de comunidade vegetal. Campinas: Instituto Agronômico, 1987. 33p. (Boletim técnico, 114).

RADIN, B.; REISSER JÚNIOR, C.; MATZENAUER, R. Crescimento de cultivares de alface conduzidas em estufa e a campo. Horticultura Brasileira, v.22, p.178-181, 2004.

RATKOWSKY, D.A. Nonlinear regression modeling: a unified practical approach. New York: Marcel Dekker, 1983. 276p.

SEGOVIA, J.F.O.; ANDRIOLO, J.L.; BURIOL, G.A.; SCHNEIDER, F.M. Comparação do crescimento e desenvolvimento da alface (Lactuca sativa $\mathrm{L}$.) no interior e no exterior de uma estufa de polietileno em Santa Maria, RS. Ciência Rural, v.27, p.37-41, 1997.

SILVA, E.L.; MARTINEZ, L.F.; YITAYEW, M. Relação entre coeficientes de cultura e graus-dia de desenvolvimento da alface. Horticultura Brasileira, v.17, p.134-142, 1999.

VAN KEULEN, H.; WOLF, J. Modelling of agricultural production: weather, soils and crops. Wageningen: Pudoc, 1986. 613p. 